\title{
An update on the unparalleled impact of FDG-PET imaging on the day-to-day practice of medicine with emphasis on management of infectious/inflammatory disorders
}

\author{
Abass Alavi ${ }^{1}$ (1) Søren Hess ${ }^{2,3} \cdot$ Thomas J. Werner $^{1}$ • Poul Flemming Høilund-Carlsen ${ }^{3,4}$ \\ Received: 6 August 2019 / Accepted: 16 August 2019/Published online: 4 September 2019 \\ (C) Springer-Verlag GmbH Germany, part of Springer Nature 2019
}

The concept of FDG-PET imaging was discussed for the first time among three investigators from the University of Pennsylvania, Abass Alavi, David Kuhl, and Martin Reivich, in the early 1970s [1]. These investigators had realized the potential for this novel radiolabeled compound in human research and clinical practice based on autoradiographic imaging studies using 14C-deoxyglucose in animals [1]. This initial discussion led to contacting chemists at the Brookhaven National Laboratory (BNL), which soon led to a joint effort to label deoxyglucose with $18 \mathrm{~F}$ and determine its role by examining brain function in human beings. This investigation was led by Alfred Wolf and his colleagues at BNL and eventually, the compound was successfully synthesized and tested for toxicity before plans were made to image its distribution in human beings [2]. By mid-1976, an investigational new drug (IND) application was secured from the FDA for administering this radiotracer to normal human volunteers. Finally, in August 1976, the compound was shipped by a private plane to Philadelphia and successful images of the whole body by a conventional rectilinear scanner and tomographic images by a SPECT instrument were acquired by Abass Alavi at the University of Pennsylvania [3]. Soon

This article is part of the Topical Collection on Editorial

Abass Alavi

abass.alavi@uphs.upenn.edu

1 Department of Radiology, Hospital of the University of Pennsylvania, 3400 Spruce Street, Philadelphia, PA 19104, USA

2 Department of Radiology and Nuclear Medicine, Hospital of Southwest Jutland, Esbjerg, Denmark

3 Department of Clinical Research, Faculty of Health Sciences, University of Southern Denmark, Odense, Denmark

4 Department of Nuclear Medicine, Odense University Hospital, Odense, Denmark thereafter, research protocols were drafted to determine the patterns of cerebral glucose metabolism with this compound in central nervous system disorders by Penn/BNL and UCLA investigators $[4,5]$. The results from these early research studies conducted initially at these institutions and then later by a few other centers in the USA and Europe in the 1980s clearly demonstrated the great promise of FDG for both research and clinical applications.

In spite of the complexity and technical challenges that were faced by this demanding technology, over the past 4 decades, the role of this powerful imaging modality has been validated and well-established for assessing numerous disorders [6, 7]. Soon after its introduction, this approach was proven to be of great value in diagnosing Alzheimer's disease with very high sensitivity and specificity which has remained unmatched by any other technique to date [8-10]. Other applications in the 1980s and 1990s included detection of seizure focus in temporal lobe epilepsy [11-13], vascular disorders [14], and a variety of neuropsychiatric diseases such as schizophrenia and manic depression [15-18]. However, the major observation that was made from the early research studies in animal [19] and in human brain images with FDG was its critical role in detecting and characterizing malignant cells, particularly, brain tumors $[20,21]$. These early research projects were carried out by investigators at BNL, Penn, and NIH. For the first time, the observation that was described by Warburg in the in vitro setting, where he was able to demonstrate high glycolytic activity of cancer cells compared with normal tissues, was verified by in vivo imaging with FDG [22, 23]. The latter further enhanced the potential for employing FDG-PET imaging to expand the horizons of this powerful methodology beyond central nervous system disorders.

In parallel with synthesis of FDG and testing its novel application in human diseases and disorders, efforts by Michael TerPogossian and colleagues at Washington University had resulted in designing and testing early PET 
instruments for imaging positron-based radiotracers [24]. The initial instruments provided images in a limited axial field of view and therefore were employed for assessing small organs such as the brain and the heart. By the early 1980s, efforts were made to assemble advanced instruments that could image the entire body with extended fields of view, which have been improved substantially over the past 3 decades [25].

Major advances that have been made in designing and building sophisticated PET instruments have further enhanced the impact of FDG-PET in many settings where imaging larger segments of the body along with structural data are essential for accurate diagnosis. In particular, the introductions of PET/ CT in 2000 [26] and PET/MRI in 2008 [27] have substantially improved the performance of PET in disciplines such as radiation therapy and surgery. These instruments have allowed precise localization of FDG-positive targeted lesions.

The introduction of total-body PET imaging during the past year by investigators at UC Davis and Penn is expected to substantially enhance the role of this powerful modality even further [28]. This instrument allows imaging of the entire body within minutes and by administering substantially lower doses of FDG than the amounts currently being administered with limited field of view PET/CT scanners. Furthermore, total body imaging is going to allow for global disease assessment in serious diseases and disorders such as atherosclerosis, osteoporosis, vascular complications of many malignancies, and systemic inflammation including rheumatoid arthritis and psoriasis.

The synthesis of FDG, which was somewhat cumbersome and limited to academic institutions, was significantly simplified over the ensuing years and this has allowed rapid expansion of this technology to most advanced centers around the world. Since the 1990s, applications of FDG-PET have expanded to include imaging various malignancies and this has resulted in the acceptance of this technology by the oncologists for the diagnosis and treatment response following various therapeutic interventions [25]. By the mid-1990s, it was noted that FDG-PET imaging could potentially play a role in the detection of infection and aseptic inflammation due to a variety of disorders [29]. In the early 2000s, studies were reported describing FDG uptake in the atherosclerotic plaques in the aorta and other major arteries [30,31]. Similarly, it was shown that clots in the venous system have substantial glycolytic activity and can be visualized by this technique [32-34]. In addition, detecting FDG uptake in the myocardium has been adopted for assessing myocardial viability before coronary artery bypass surgery $[35,36]$. Therefore, over the past 2 decades, the domain for FDG-PET applications has expanded substantially and, in fact, the rate of expansion of this technology has exceeded that of any other modern imaging techniques in recent years [7]. Moreover, the molecular dimension and the ability to overlook major parts of the body in a single examination séance are going to change and improve our understanding of many diseases as exemplified by FDGPET findings of significant vasculitis inside the body in what until now was considered a serious skin disease, namely psoriasis [37]. In addition, the superior sensitivity of PET and targeting at the molecular level opens for much earlier disease detection than with conventional structural imaging. A striking example of that is the detection of bone marrow instead of bone metastases by means of FDG-PET probably months or years before changes in the skeletal bone matrix become apparent by CT imaging, where they may persist even after active cancer cells are no longer present [38].

In contrast to CT and MRI, which were adopted without any hesitation, the medical community was reluctant to accept the validity of exploring PET as a viable modality for assessing any of the diseases and disorders enumerated above. In fact, early applications of PET were primarily supported by grants from the NIH, other government agencies, foundations, and institutional funding. It was not until 1998 when Medicare (US Government Insurance Agent) approved the use of this technology for characterizing lung nodules and for initial staging of non-small cell lung cancer (NSCLC). Fortunately, over the past decade, Medicare has expanded its coverage of PET for most malignancies and this has allowed rapid expansion of this technology particularly in the USA $[39,40]$. In fact, without the latter initiative, PET would have never survived as a viable imaging technique. Unfortunately, clinical acceptance of FDG-PET as a very powerful method for assessing infection and inflammation has been somewhat slow and limited to centers where research funding has been secured from various agencies [41-47]. This is very disappointing since, based on reports that have appeared in the literature, FDG-PET imaging appears to be the most successful imaging approach for detection and characterization of many infectious and inflammatory disorders [7]. Efforts are being made to educate both the scientific and clinical communities about the unparalleled role of this technique in such domains.

Finally, FDG-PET is the most quantitative imaging technique for assessing disease activity in medicine, and as such, it contributes enormously to determine the course of disease and the effectiveness of various interventions [48]. Particularly, its ability to provide a single value as evidence for global disease activity is essential for overall assessment of multiple benign and malignant disorders [49]. Previously, the mentioned limited fields of view was a hindrance to such overall assessments, but with the extended fields of modern scanners, their higher sensitivity and correspondingly shorter image acquisition times, not to mention the advent of the total-body PET scanner [28], the concept of providing a global disease score (GDS) representing the extension and severity of disease in part of (D) or in the total body has come into reach as illustrated in Fig. 1 in a HIV/TB-positive patient. Until recently, to provide such scores have often been too time-consuming for application in the daily routine since it requires careful 
a

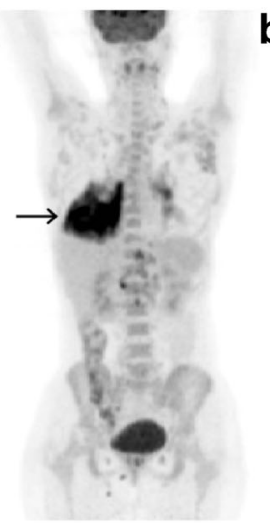

b

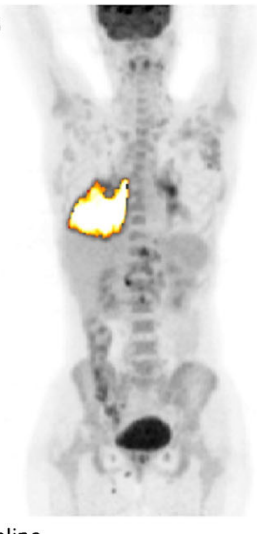

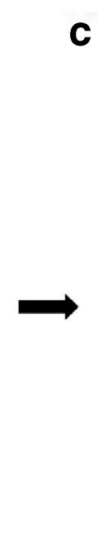

C

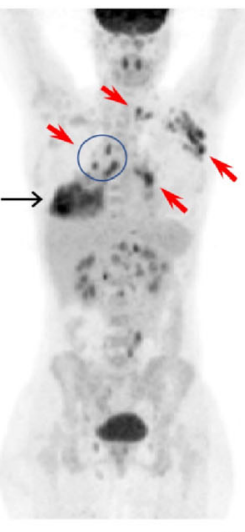

d

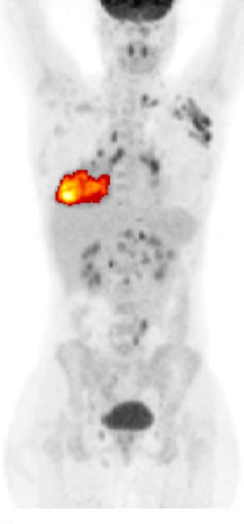

\begin{tabular}{ccccccc}
\multicolumn{1}{c}{ Baseline } & \multicolumn{3}{c}{ Follow up } \\
\hline & MTV & SUVmean & pvcSUVmean & SUVmax & TLG & pvcTLG \\
\hline Baseline & 184.4 & 9.3 & 12.1 & 14.9 & 1727.2 & 2238.6 \\
Follow up & 87.4 & 6.8 & 9.4 & 11.4 & 597.6 & 830.5 \\
\hline
\end{tabular}

Fig. 1 Baseline (a, b) and follow-up (c, d) maximum intensity projection (MIP) PET images of an HIV/TB-positive patient. The lung lesion decreased in size and disease activity following 2 months of antiretroviral therapy (black arrows). Coincident with response to treatment in the lung lesion, an increased lymph node reaction was observed on FDG-PET scan (red arrows). The FDG-avid lung inflammatory site was segmented semi-automatically using an adaptive

segmentation of all disease areas and lesions in the body, which implies great observer experience and, in particular, when it comes to small lesions, correction for partial volume effect. However, with the rapid introduction of artificial intelligence-based systems for quantitative, observerindependent processing of PET images in seconds or a few minutes, overall disease assessment will become a major target for future clinical research and implementation [49].

In this review, we will describe in great detail the role of FDG in a variety of infectious and inflammatory disorders.

Early in the history of FDG-PET imaging, occasional reports of false-positive findings due to infection or inflammation in patients with malignant tumors were a nuisance to oncologists who had to realize that FDG was not a cancerspecific tracer [50]. It has now been established that this is because cells involved in the inflammatory response (e.g., neutrophils, macrophages, and activated leukocytes) similar to malignant cells often express high levels of glucose transporters. In addition, circulating cytokines seem to increase the affinity of these glucose transporters for FDG [51, 52]. Tahara et al. reported on the first cases using FDG directly for imaging infection with increased accumulation in abdominal abscesses in humans [53], and since then, there has been a growing interest in using PET and PET/CT for the study of infectious and inflammatory diseases $[29,54,55]$. Generally speaking, the use of FDG and PET in infectious and inflammatory diseases can be divided into systemic whole-body diseases and focused, organ- or symptom-specific diagnostics.

In the former category falls one of the most wellestablished indications, namely fever of unknown origin contrast-oriented thresholding system (ROVER; ABBX, Radeberg, Germany). The values for metabolic tumor volume (MTV), SUVmean, partial volume corrected SUVmean (pvcSUVmean), SUVmax, total lesion glycolysis (TLG), and partial volume corrected total lesion glycolysis (pvcTLG) at the baseline and the follow-up are noted in the table. (These images are courtesy of Professor Mboyo-Di-Tamba Vangu, University of the Witwatersrand, Johannesburg)

(FUO), a heterogeneous group of diseases with a multitude of differential diagnoses, i.e., infectious, malignant, or inflammatory diseases all with an element of hypermetabolism. Patients often present with unspecific symptoms and few diagnostic clues, and it may be challenging to reach an etiologic diagnosis [56, 57]. Whole-body FDG-PET/CT is sensitive in guiding the clinician towards more specific investigations and provides clinically helpful and important information towards reaching a diagnosis in overall $50-60 \%$ of patients (i.e., $42-$ $92 \%$ of cases depending on how the authors define "helpful"), substantially better than any other diagnostic procedure [58, 59]. Also, one must remember that the underlying studies usually include patients without a firm diagnosis after a multitude of other diagnostic procedures, i.e., often the most difficult patients.

Another challenging whole-body ailment is bacteremia of unknown origin; early studies found clinically relevant findings in up to half of patients with bacteremia of unknown origin or suspected metastatic spread with high positive and negative predictive values $[60,61]$ and established FDG-PET/ $\mathrm{CT}$ to be cost-effective due to significantly lower relapse rates and mortality $[62,63]$. More recent studies have corroborated these initial findings in heterogeneous settings of bacteremia of unknown origin with PET leading to change in clinical management in half of the patients, also after prolonged febrile periods in patients heavily pretreated with antibiotics [64]. FDG-PET/CT has also been shown to have a direct therapeutic consequence in one-third of critically ill septicemic patients with unknown etiology [65], and high sensitivity and significant clinical impact in $53-75 \%$ of 
immunocompromised patients with febrile neutropenia [66, 67]. Another entity with potential metastatic infection is infective endocarditis (IE), especially prosthetic valve endocarditis; focal FDG uptake in the valve area may be indicative of endocarditis, often an incidental finding in FUO or equivocal cases, but imaging the heart is difficult without prolonged fasting due to the physiologic myocardial uptake of FDG; thus, FDG-PET may better contribute in infective endocarditis by detecting clinically occult metastatic infectious foci, as an adjunct to echocardiography in equivocal cases, or in suspected cardiac device infection [68-71].

Looking at more specific indications, FDG-PET/CT is second to none in chronic osteomyelitis; a meta-analysis pooling data from 23 studies found FDG-PET had the highest accuracy in diagnosing and excluding chronic osteomyelitis, with a sensitivity of $96 \%$ and a specificity of $91 \%$, compared with $78 \%$ and $84 \%$ with combined bone and leucocyte scintigraphy, and $84 \%$ and $60 \%$ with MRI [72]. Similarly, with spondylodiscitis, a meta-analysis found sensitivity and specificity of $97 \%$ and $88 \%$, respectively [73], and a recent study established that FDG-PET/CT is especially adept in the early phase with sensitivity of $96 \%$ compared with $50 \%$ with MRI within the first 2 weeks after symptom debut [74]. Although it only represents $2-4 \%$ of osteomyelitis cases, structural imaging may be insufficient in spondylodiscitis, because morphologic changes are often nonspecific and discrimination between infection and degenerative changes is challenging. Although the specificity of FDG-PET may be lower in the initial postoperative period due to unspecific inflammation [75], excellent results are achievable in patients with suspected spinal infection related to metallic implants, i.e., overall sensitivity, specificity, and accuracy in the range of 94-100\%, 87-93\%, and 91-97\%, respectively, with corresponding results for patients with metallic implants: $91 \%$, $71 \%$, and $83 \%$, respectively - in one study, FDG-PET was found to increase the physician's confidence, which added significantly to the clinical decision-making process and treatment strategy in two-thirds of patients [76, 77].

FDG-PET has also been employed in the diagnosis of prosthetic joint infections. Although still controversial, several meta-analyses as well as prospective comparisons have demonstrated more robust results with FDG-PET (i.e., pooled sensitivity and specificity of $70-95 \%$ and $84-93 \%$, respectively) compared with combinations of white blood cell scintigraphy and bone marrow scintigraphy (i.e., pooled sensitivity and specificity of 33-80\% and 93-96\%, respectively) [47, 78-81].

Finally, several studies have pointed to FDG-PET as a useful modality in the diagnostic challenging diabetic foot. One study reported lower sensitivity but higher specificity and accuracy with FDG-PET than with MRI [82], while another found both higher sensitivity and accuracy with FDG-PET, concluding that this method was able to reliably differentiate Charcot's neuroarthropathy from osteomyelitis [45]. A recent prospective study found that FDG-PET/CT imaging of the diabetic foot had a sensitivity, specificity, and accuracy of $100 \%, 92 \%$, and $95 \%$, respectively, in the diagnosis of osteomyelitis [83].

Vascular graft infection is a rare but serious complication carrying high mortality and morbidity with a substantial risk of limb loss or death [84, 85]. It is often difficult to distinguish morphologically between graft infection, non-infected hematoma, and lymphocele. While CT has low sensitivity in lowgrade infections, FDG-PET may lack specificity. In the first hybrid PET/CT study, Keidar et al. found excellent sensitivity and specificity of $93 \%$ and $91 \%$, respectively [86]. Whereas subsequent studies generally confirmed the high sensitivity, specificities varied considerably, i.e., two recent metaanalyses found pooled sensitivities and specificities of 95$97 \%$ and $80-89 \%$, respectively, with confidence intervals for specificities ranging from 69-96\%. Even so, FDG-PET/CT generally performs much better than CT with several studies finding both sensitivities and specificities in the 55-65\% range only $[85,87]$. However, several caveats pertain to the available FDG-PET literature, e.g., patient populations are generally a heterogeneous mix of acute and chronic, lowgrade infections, various graft types, and most are heavily pretreated with antibiotics. Also, methodologies are generally suboptimal with regard to a reference standard and a lack of consensus on interpretation strategy.

Due to the nonspecific nature of FDG, more infectionspecific tracers are desirable. A multitude of alternative candidates has been assessed preclinically, including several different isotopes (e.g., ${ }^{64} \mathrm{Cu},{ }^{68} \mathrm{Ga}$, and ${ }^{124} \mathrm{I}$ ). Although results have been promising and scientifically interesting, a recent systematic review established a significant lack of standardization in the preclinical settings and that only few have been translated into humans and with disappointing results [88].

Besides mere diagnosis, the use of FDG-PET/CT for response evaluations of treatments for infectious diseases has also been explored, albeit to a much lesser extent than in malignant diseases, e.g., spondylodiscitis [89], vascular graft infections [90, 91], and tuberculosis [92]; results have been promising, but further and larger prospective studies are warranted in this setting.

Non-infectious inflammation is also FDG-avid by mechanisms similar to those of infectious diseases, i.e., higher glucose transporter expression in inflammatory cells and increased affinity of the glucose transporters for FDG under the influence of circulating cytokines $[46,93]$. Most validated clinically is vasculitis characterized by inflammation and necrosis of the vessel wall, most commonly affects large- and medium-sized arteries, e.g., giant cell arteritis (GCA) and Takayasu's arteritis [94]. In GCA, biopsy of the temporal artery remains the reference standard, but false-negative results are seen in as many as $40 \%$ of patients [93]. Furthermore, a significant proportion of patients have extra-cranial disease 
Fig. 2 Introduction of X-ray to medicine by Röntgen in 1895

(left) has had a substantial impact on the day-to-day practice of medicine. Similarly, imaging with FDG (right) has been another major step forward by enhancing the role of medical imaging and this has led to an unparalleled impact on both research and patient care
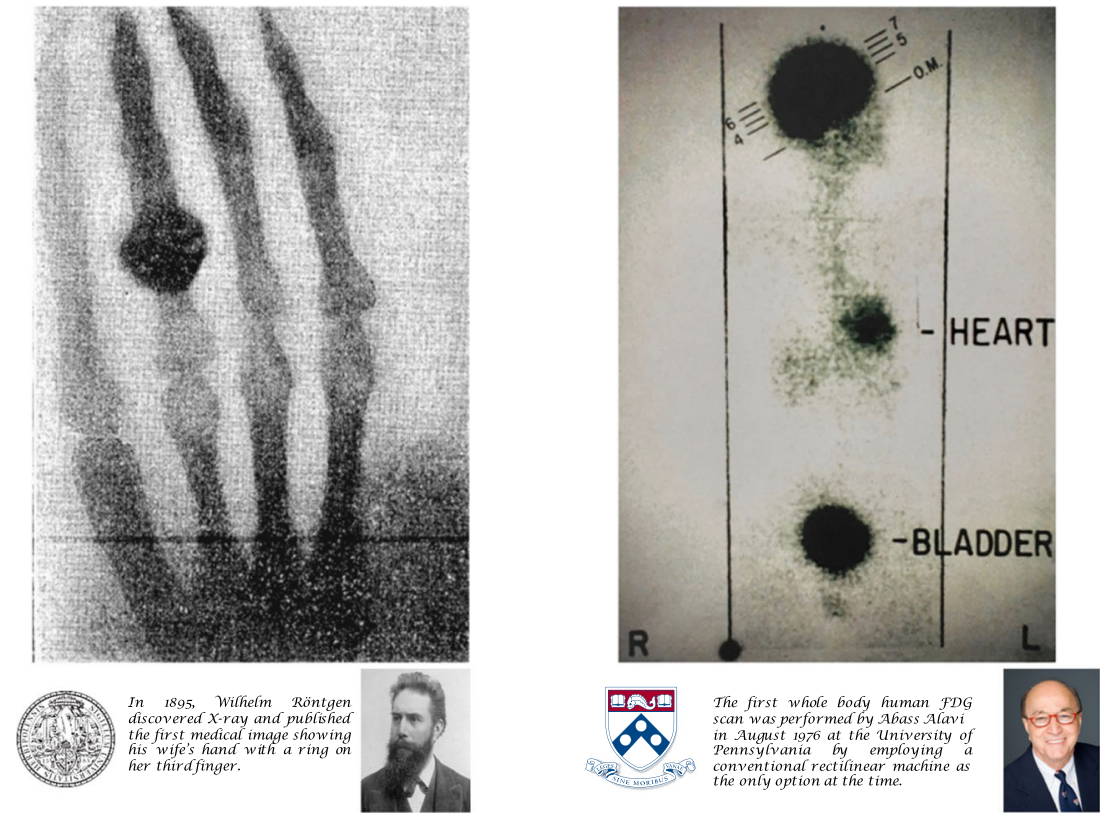

manifestations, and thus, imaging remains important to help locate suitable biopsy sites and assess disease extent and response to treatment. Evidence on FDG-PET in GCA is mounting, and recent systematic reviews have found sensitivities and specificities of 80-90\% and 89-98\% [95, 96], respectively, in GCA, and 70-87\% and 73-84\%, respectively, in Takayasu's arteritis [96-98]. Earlier studies underlined problems with visualizing the smaller arteries in the head-and-neck including the temporal artery because of its small caliber and proximity to physiologic uptake in the adjacent brain, but a recent study found high diagnostic accuracy for GCA using a dichotomous assessment of FDG uptake in cranial arteries [99]. A well-known pitfall is glucocorticoid treatment known to hamper FDG uptake and leading to false-negative scans, but another recent study found remaining high sensitivity within the first 3 days of high-dose glucocorticoids, whereas sensitivity was significantly reduced after 10-day treatment [100]. Polymyalgia rheumatica is a systemic disease entity characterized by soft tissue inflammation, synovitis, and bursitis, and is often associated with large-vessel vasculitis. As with GCA, available imaging has been sparse, but in recent years, several reports have proposed several well-defined anatomical areas related to bursae and axial joints where increased FDG uptake is associated with polymyalgia rheumatica [101-103].

Reports on FDG uptake in sarcoidosis emerged in the early 1990s, and whole-body FDG-PET is a sensitive marker of sarcoidosis activity $[104,105]$. Although not the modality of choice in the initial diagnostic workup due to its inability to differentiate benign granulomatous disease from lymphoma, a systematic review identified nine studies with a total of 379 patients and reported great potential in several areas, e.g., assessing disease activity and thus aiding the monitoring of treatment response as early as 6 weeks following initiation of therapy, and for staging and detection of sites that are clinically occult [106]. Also, FDG may have a role in cardiac sarcoidosis, but the same caveats as with infective endocarditis apply, i.e., patient preparation is pivotal to suppress physiologic uptake in the myocardium [107, 108].

Several other inflammatory diseases have been suggested and investigated using FDG-PET with potential, but evidence is still equivocal. These include inflammatory bowel disease where physiologic FDG uptake may complicate matters, but two meta-analyses found overall sensitivity and specificity of $84-85 \%$ and $86-87 \%$, respectively $[109,110]$. A possible application is a differentiation between inflammatory and fibrostenotic strictures with obvious advantages for treatment planning and avoiding invasive surgical procedures [111]. All of this could be of special significance in pediatric inflammatory bowel disease [112]. Also, FDG has been suggested to detect and assess inflammatory joint disorders [113], also for monitoring treatment response because morphologic assessment of synovial thickening is difficult [114], but important with the effective but expensive new biological drugs that may present serious side effects [115]. Finally, FDG has been proposed in venous thromboembolism (VTE) as commonly used diagnostic imaging techniques do not address some of the important aspects of this disease [32]: VTE may present in the entire venous vasculature, but routine imaging only assesses lower extremity veins and pulmonary arteries; an underlying disease like cancer is often a key factor in the development of VTE, but patients are not examined routinely to 
disclose this; and differentiating acute from chronic VTE is impossible by routine imaging, but has profound influence on treatment strategy. A recent systematic review has summarized the potential within all of the mentioned domains, but the literature is still too sparse for firm conclusions [116].

The enormous impact of FDG-PET imaging on many disciplines of medicine competes with any other major development to date. The increasing number of newer applications of FDG for assessing diseases beyond cancer has significantly improved patient care far beyond any other imaging technique over the past decades. As it becomes more and more evident that contrast agents designed for CT and MRI are associated with serious side effects, it is conceivable that FDG will be used in place of these radiologic contrast agents in the future. In addition, the introduction of FDG has resulted in the survival of PET as an imaging modality and made PET as the most powerful imaging technique to assess disease processes at the molecular level. Furthermore, the survival of PET as such a powerful modality has resulted in the development of new radiotracers that are revolutionizing our ability to assess many diseases and disorders at the molecular level. These advances are going to be essential for characterizing the underlying causes of numerous maladies and developing potential approaches for therapeutic interventions. As such, it may be appropriate to portray the introduction of FDG-PET to medicine as compared with that of X-ray by Roentgen in 1895 (Fig. 2).

\section{Compliance with ethical standards}

Conflict of interest The authors declare that they have no conflict of interest.

Ethical approval This article does not contain any studies with human participants or animals performed by any of the authors.

\section{References}

1. Alavi A, Reivich M. Guest editorial: the conception of FDG-PET imaging. Semin Nucl Med. 2002;32:2-5. https://doi.org/10.1053/ snuc.2002.29269.

2. Ido T, Wan C-N, Casella V, Fowler JS, Wolf AP, Reivich M, et al. Labeled 2-deoxy-D-glucose analogs. 18F-labeled 2-deoxy-2fluoro-D-glucose, 2-deoxy-2-fluoro-D-mannose and 14C-2-deoxy-2-fluoro-D-glucose. J Label Compd Radiopharm. 1978;14: 175-83. https://doi.org/10.1002/jlcr.2580140204.

3. Hess S, Hoilund-Carlsen PF, Alavi A. Historic images in nuclear medicine: 1976: the first issue of clinical nuclear medicine and the first human FDG study. Clin Nucl Med. 2014;39:701-3. https:// doi.org/10.1097/rlu.0000000000000487.
4. Alavi A, Reivich M, Greenberg J, Hand P, Rosenquist A, Rintelmann W, et al. Mapping of functional activity in brain with 18F-fluoro-deoxyglucose. Semin Nucl Med. 1981;11:24-31.

5. Alavi A, Hirsch LJ. Studies of central nervous system disorders with single photon emission computed tomography and positron emission tomography: evolution over the past 2 decades. Semin Nucl Med. 1991;21:58-81.

6. Basu S, Alavi A. Unparalleled contribution of 18F-FDG PET to medicine over 3 decades. J Nucl Med. 2008;49:17N-21N 37N.

7. Hess S, Blomberg BA, Zhu HJ, Hoilund-Carlsen PF, Alavi A. The pivotal role of FDG-PET/CT in modern medicine. Acad Radiol. 2014;21:232-49. https://doi.org/10.1016/j.acra.2013.11.002.

8. Khosravi M, Newberg A, Alavi A. Cognitive impairment and dementias. Semin Nucl Med. 2018;48:498-512. https://doi.org/ 10.1053/j.semnuclmed.2018.07.005.

9. Khosravi M, Peter J, Wintering NA, Serruya M, Shamchi SP, Werner TJ, et al. 18F-FDG is a superior indicator of cognitive performance compared to 18F-florbetapir in Alzheimer's disease and mild cognitive impairment evaluation: a global quantitative analysis. J Alzheimers Dis. 2019. https://doi.org/10.3233/jad190220.

10. Hoilund-Carlsen PF, Barrio JR, Gjedde A, Werner TJ, Alavi A. Circular inference in dementia diagnostics. J Alzheimers Dis. 2018;63:69-73. https://doi.org/10.3233/jad-180050.

11. Meyer PT, Cortes-Blanco A, Pourdehnad M, Levy-Reis I, Desiderio L, Jang S, et al. Inter-modality comparisons of seizure focus lateralization in complex partial seizures. Eur J Nucl Med. 2001;28:1529-40. https://doi.org/10.1007/s002590100602.

12. Wolf RL, Alsop DC, Levy-Reis I, Meyer PT, Maldjian JA, Gonzalez-Atavales J, et al. Detection of mesial temporal lobe hypoperfusion in patients with temporal lobe epilepsy by use of arterial spin labeled perfusion MR imaging. AJNR Am J Neuroradiol. 2001;22:1334-41.

13. Peter J, Houshmand S, Werner TJ, Rubello D, Alavi A. Novel assessment of global metabolism by 18F-FDG-PET for localizing affected lobe in temporal lobe epilepsy. Nucl Med Commun. 2016;37:882-7. https://doi.org/10.1097/mnm. 0000000000000526 .

14. Moghbel M, Al-Zaghal A, Werner TJ, Constantinescu CM, Hoilund-Carlsen PF, Alavi A. The role of PET in evaluating atherosclerosis: a critical review. Semin Nucl Med. 2018;48:488-97. https://doi.org/10.1053/j.semnuclmed.2018.07.001.

15. Kumar A, Newberg A, Alavi A, Berlin J, Smith R, Reivich M. Regional cerebral glucose metabolism in late-life depression and Alzheimer disease: a preliminary positron emission tomography study. Proc Natl Acad Sci U S A. 1993;90:7019-23.

16. Gur RE, Resnick SM, Alavi A, Gur RC, Caroff S, Dann R, et al. Regional brain function in schizophrenia. I. A positron emission tomography study. Arch Gen Psychiatry. 1987;44:119-25. https:// doi.org/10.1001/archpsyc.1987.01800140021003.

17. Gur RE, Resnick SM, Gur RC, Alavi A, Caroff S, Kushner M, et al. Regional brain function in schizophrenia. II. Repeated evaluation with positron emission tomography. Arch Gen Psychiatry. 1987;44:126-9. https://doi.org/10.1001/archpsyc.1987. 01800140028004.

18. Resnick SM, Gur RE, Alavi A, Gur RC, Reivich M. Positron emission tomography and subcortical glucose metabolism in schizophrenia. Psychiatry Res. 1988;24:1-11.

19. Som P, Atkins HL, Bandoypadhyay D, Fowler JS, MacGregor $\mathrm{RR}$, Matsui $\mathrm{K}$, et al. A fluorinated glucose analog, 2-fluoro-2deoxy-D-glucose (F-18): nontoxic tracer for rapid tumor detection. J Nucl Med. 1980;21:670-5. 
20. Alavi JB, Alavi A, Chawluk J, Kushner M, Powe J, Hickey W, et al. Positron emission tomography in patients with glioma. A predictor of prognosis. Cancer. 1988;62:1074-8.

21. Patronas NJ, Di Chiro G, Kufta C, Bairamian D, Kornblith PL, Simon R, et al. Prediction of survival in glioma patients by means of positron emission tomography. J Neurosurg. 1985;62:816-22. https://doi.org/10.3171/jns.1985.62.6.0816.

22. Warburg O. On the origin of cancer cells. Science (New York, NY). 1956;123:309-14.

23. Warburg O, Wind F, Negelein E. The metabolism of tumors in the body. J Gen Physiol. 1927;8:519-30.

24. Ter-Pogossian MM, Phelps ME, Hoffman EJ, Mullani NA. A positron-emission transaxial tomograph for nuclear imaging (PETT). Radiology. 1975;114:89-98. https://doi.org/10.1148/ 114.1.89.

25. Hustinx R, Benard F, Alavi A. Whole-body FDG-PET imaging in the management of patients with cancer. Semin Nucl Med. 2002;32:35-46. https://doi.org/10.1053/snuc.2002.29272.

26. Beyer T, Townsend DW, Brun T, Kinahan PE, Charron M, Roddy $\mathrm{R}$, et al. A combined PET/CT scanner for clinical oncology. J Nucl Med. 2000;41:1369-79.

27. Antoch G, Bockisch A. Combined PET/MRI: a new dimension in whole-body oncology imaging? Eur J Nucl Med Mol Imaging. 2009;36(Suppl 1):S113-20. https://doi.org/10.1007/s00259-0080951-6.

28. Badawi RD, Shi H, Hu P, Chen S, Xu T, Price PM, et al. First human imaging studies with the EXPLORER Total-Body PET Scanner. J Nucl Med. 2019;60:299-303. https://doi.org/10.2967/ jnumed.119.226498.

29. Zhuang H, Alavi A. 18-fluorodeoxyglucose positron emission tomographic imaging in the detection and monitoring of infection and inflammation. Semin Nucl Med. 2002;32:47-59. https://doi. org/10.1053/snuc.2002.29278.

30. Yun M, Yeh D, Araujo LI, Jang S, Newberg A, Alavi A. F-18 FDG uptake in the large arteries: a new observation. Clin Nucl Med. 2001;26:314-9.

31. Yun M, Jang S, Cucchiara A, Newberg AB, Alavi A. 18F FDG uptake in the large arteries: a correlation study with the atherogenic risk factors. Semin Nucl Med. 2002;32:70-6. https://doi.org/10. 1053/snuc.2002.29279.

32. Hess S, Madsen PH, Basu S, Hoilund-Carlsen PF, Alavi A. Potential role of FDG PET/CT imaging for assessing venous thromboembolic disorders. Clin Nucl Med. 2012;37:1170-2. https://doi.org/10.1097/RLU.0b013e318279bf73.

33. Sydow BD, Srinivas SM, Newberg A, Alavi A. Deep venous thrombosis on F-18 FDG PET/CT imaging. Clin Nucl Med. 2006;31:403-4. https://doi.org/10.1097/01.rlu.0000222950. 98284.94.

34. Sharma P, Kumar R, Singh H, Jeph S, Patnecha M, Reddy RM, et al. Imaging thrombus in cancer patients with FDG PET-CT. Jpn J Radiol. 2012;30:95-104. https://doi.org/10.1007/s11604-0110016-9.

35. Schelbert HR, Henze E, Phelps ME, Kuhl DE. Assessment of regional myocardial ischemia by positron-emission computed tomography. Am Heart J. 1982;103:588-97.

36. Schelbert HR, Schwaiger M. Positron emission tomography in human myocardial ischemia. Herz. 1987;12:22-40.

37. Mehta NN, Yu Y, Saboury B, Foroughi N, Krishnamoorthy $\mathrm{P}$, Raper A, et al. Systemic and vascular inflammation in patients with moderate to severe psoriasis as measured by [18F]-fluorodeoxyglucose positron emission tomographycomputed tomography (FDG-PET/CT): a pilot study. Arch
Dermatol. 2011;147:1031-9. https://doi.org/10.1001/ archdermatol.2011.119.

38. Hoilund-Carlsen PF, Hess S, Werner TJ, Alavi A. Cancer metastasizes to the bone marrow and not to the bone: time for a paradigm shift! Eur J Nucl Med Mol Imaging. 2018;45:893-7. https:// doi.org/10.1007/s00259-018-3959-6.

39. Coleman RE, Hillner BE, Shields AF, Duan F, Merlino DA, Hanna LG, et al. PET and PET/CT reports: observations from the National Oncologic PET Registry. J Nucl Med. 2010;51: 158-63. https://doi.org/10.2967/jnumed.109.066399.

40. Siegel BA. Cassen Lecture: what have we learned from the National Oncologic PET Registry? J Nucl Med. 2014;55:9n-15n.

41. Zhuang H, Duarte PS, Pourdehnad M, Maes A, Van Acker F, Shnier D, et al. The promising role of $18 \mathrm{~F}-\mathrm{FDG}$ PET in detecting infected lower limb prosthesis implants. J Nucl Med. 2001;42:44-8.

42. Hochhold J, Yang H, Zhuang H, Alavi A. Application of 18Ffluorodeoxyglucose and PET in evaluation of the diabetic foot. PET Clin. 2006;1:123-30. https://doi.org/10.1016/j.cpet.2006. 03.001 .

43. Kumar R, Basu S, Torigian D, Anand V, Zhuang H, Alavi A. Role of modern imaging techniques for diagnosis of infection in the era of 18F-fluorodeoxyglucose positron emission tomography. Clin Microbiol Rev. 2008;21:209-24. https://doi.org/10.1128/cmr. 00025-07.

44. Basu S, Zhuang H, Alavi A. FDG PET and PET/CT Imaging in complicated diabetic foot. PET Clin. 2012;7:151-60. https://doi. org/10.1016/j.cpet.2012.01.003.

45. Basu S, Chryssikos T, Houseni M, Scot Malay D, Shah J, Zhuang $\mathrm{H}$, et al. Potential role of FDG PET in the setting of diabetic neuroosteoarthropathy: can it differentiate uncomplicated Charcot's neuroarthropathy from osteomyelitis and soft-tissue infection? Nucl Med Commun. 2007;28:465-72. https://doi.org/10.1097/ MNM.0b013e328174447f.

46. Basu S, Chryssikos T, Moghadam-Kia S, Zhuang H, Torigian DA, Alavi A. Positron emission tomography as a diagnostic tool in infection: present role and future possibilities. Semin Nucl Med. 2009;39:36-51. https://doi.org/10.1053/j. semnuclmed.2008.08.004.

47. Basu S, Kwee TC, Saboury B, Garino JP, Nelson CL, Zhuang H, et al. FDG PET for diagnosing infection in hip and knee prostheses: prospective study in 221 prostheses and subgroup comparison with combined (111)in-labeled leukocyte/(99m)Tc-sulfur colloid bone marrow imaging in 88 prostheses. Clin Nucl Med. 2014;39: 609-15. https://doi.org/10.1097/rlu.0000000000000464.

48. Houshmand S, Salavati A, Hess S, Werner TJ, Alavi A, Zaidi H. An update on novel quantitative techniques in the context of evolving whole-body PET imaging. PET Clin. 2015;10:45-58. https://doi.org/10.1016/j.cpet.2014.09.004.

49. Hoilund-Carlsen PF, Edenbrandt L, Alavi A. Global disease score (GDS) is the name of the game! Eur J Nucl Med Mol Imaging. 2019;46:1768-72. https://doi.org/10.1007/s00259-019-04383-8.

50. Larson SM. Cancer or inflammation? A Holy Grail for nuclear medicine. J Nucl Med. 1994;35:1653-5.

51. Yamada S, Kubota K, Kubota R, Ido T, Tamahashi N. High accumulation of fluorine-18-fluorodeoxyglucose in turpentine-induced inflammatory tissue. J Nucl Med. 1995;36:1301-6.

52. Sugawara Y, Gutowski TD, Fisher SJ, Brown RS, Wahl RL. Uptake of positron emission tomography tracers in experimental bacterial infections: a comparative biodistribution study of radiolabeled FDG, thymidine, L-methionine, 67Ga-citrate, and 125I-HSA. Eur J Nucl Med. 1999;26:333-41. 
53. Tahara T, Ichiya Y, Kuwabara Y, Otsuka M, Miyake Y, Gunasekera R, et al. High [18F]-fluorodeoxyglucose uptake in abdominal abscesses: a PET study. J Comput Assist Tomogr. 1989;13:829-31.

54. Hess S, Alavi A, Basu S. PET-based personalized management of infectious and inflammatory disorders. PET Clin. 2016;11:35161. https://doi.org/10.1016/j.cpet.2016.02.008.

55. Zhuang H, Yu JQ, Alavi A. Applications of fluorodeoxyglucosePET imaging in the detection of infection and inflammation and other benign disorders. Radiol Clin N Am. 2005;43:121-34. https://doi.org/10.1016/j.rcl.2004.07.005.

56. Knockaert DC, Vanderschueren S, Blockmans D. Fever of unknown origin in adults: 40 years on. J Intern Med. 2003;253: 263-75.

57. Al-Zaghal A, Raynor WY, Seraj SM, Werner TJ, Alavi A. FDGPET imaging to detect and characterize underlying causes of fever of unknown origin: an unavoidable path for the foreseeable future. Eur J Nucl Med Mol Imaging. 2019;46:2-7. https://doi.org/10. 1007/s00259-018-4164-3.

58. Israel $\mathrm{O}$, Keidar Z. PET/CT imaging in infectious conditions. Ann N Y Acad Sci. 2011;1228:150-66. https://doi.org/10.1111/j.17496632.2011.06026.x.

59. Hess SHS, Pedersen KT, Basu S, Høilund-Carlsen PF. FDG$\mathrm{PET} / \mathrm{CT}$ in infectious and inflammatory diseases. PET Clin. 2014;9:497-519.

60. Bleeker-Rovers CP, Vos FJ, Wanten GJ, van der Meer JW, Corstens FH, Kullberg BJ, et al. 18F-FDG PET in detecting metastatic infectious disease. J Nucl Med. 2005;46:2014-9.

61. Hess S, Vind SH, Skarphedinsson S, Pedersen C, Kolmos HJ, Gerke O, et al. Clinical value of PET/CT in bacteraemia of unknown origin. Results from an observational pilot study. Eur J Nucl Med Mol Imaging. 2010;37:S468. https://doi.org/10.1007/ s00259-010-1559-1.

62. Vos FJ, Bleeker-Rovers CP, Kullberg BJ, Adang EM, Oyen WJ. Cost-effectiveness of routine (18)F-FDG PET/CT in high-risk patients with gram-positive bacteremia. J Nucl Med. 2011;52:16738. https://doi.org/10.2967/jnumed.111.089714.

63. Vos FJ, Bleeker-Rovers CP, Sturm PD, Krabbe PF, van Dijk AP, Cuijpers ML, et al. 18F-FDG PET/CT for detection of metastatic infection in gram-positive bacteremia. J Nucl Med. 2010;51: 1234-40. https://doi.org/10.2967/jnumed.109.072371.

64. Brondserud MB, Pedersen C, Rosenvinge FS, Hoilund-Carlsen $\mathrm{PF}$, Hess S. Clinical value of FDG-PET/CT in bacteremia of unknown origin with catalase-negative gram-positive cocci or Staphylococcus aureus. Eur J Nucl Med Mol Imaging. 2019;46: 1351-8. https://doi.org/10.1007/s00259-019-04289-5.

65. Kluge S, Braune S, Nierhaus A, Wichmann D, Derlin T, Mester J, et al. Diagnostic value of positron emission tomography combined with computed tomography for evaluating patients with septic shock of unknown origin. J Crit Care. 2012;27:316 e1-7. https:// doi.org/10.1016/j.jcrc.2011.10.004.

66. Guy SD, Tramontana AR, Worth LJ, Lau E, Hicks RJ, Seymour JF, et al. Use of FDG PET/CT for investigation of febrile neutropenia: evaluation in high-risk cancer patients. Eur J Nucl Med Mol Imaging. 2012;39:1348-55. https://doi.org/10.1007/s00259-0122143-7.

67. Gafter-Gvili A, Paul M, Bernstine H, Vidal L, Ram R, Raanani P, et al. The role of (1)(8)F-FDG PET/CT for the diagnosis of infections in patients with hematological malignancies and persistent febrile neutropenia. Leuk Res. 2013;37:1057-62. https://doi.org/ 10.1016/j.leukres.2013.06.025.
68. Rewers KISA, Thomassen A, Hess S. The role of 18F-FDG-PET/ $\mathrm{CT}$ in infectious endocarditis and cardiac device infection. Curr Mol Imaging. 2014;3.

69. Scholtens AM, Budde RPJ, Lam M, Verberne HJ. FDG PET/CT in prosthetic heart valve endocarditis: there is no need to wait. J Nucl Cardiol. 2017;24:1540-1. https://doi.org/10.1007/s12350017-0938-4.

70. Scholtens AM, Swart LE, Verberne HJ, Tanis W, Lam MG, Budde RP. Confounders in FDG-PET/CT imaging of suspected prosthetic valve endocarditis. J Am Coll Cardiol Img. 2016;9:1462-5. https://doi.org/10.1016/j.jcmg.2016.01.024.

71. Millar BC, Prendergast BD, Alavi A, Moore JE. (18)FDG-positron emission tomography (PET) has a role to play in the diagnosis and therapy of infective endocarditis and cardiac device infection. Int J Cardiol. 2013;167:1724-36. https://doi.org/10.1016/j.ijcard. 2012.12.005.

72. Termaat MF, Raijmakers PG, Scholten HJ, Bakker FC, Patka P, Haarman HJ. The accuracy of diagnostic imaging for the assessment of chronic osteomyelitis: a systematic review and meta-analysis. J Bone Joint Surg Am. 2005;87:2464-71. https://doi.org/10. 2106/jbjs.d.02691.

73. Prodromou ML, Ziakas PD, Poulou LS, Karsaliakos P, Thanos L, Mylonakis E. FDG PET is a robust tool for the diagnosis of spondylodiscitis: a meta-analysis of diagnostic data. Clin Nucl Med. 2014. https://doi.org/10.1097/rlu.0000000000000336.

74. Smids C, Kouijzer IJ, Vos FJ, Sprong T, Hosman AJ, de Rooy JW, et al. A comparison of the diagnostic value of MRI and (18)FFDG-PET/CT in suspected spondylodiscitis. Infection. 2017;45: 41-9. https://doi.org/10.1007/s15010-016-0914-y.

75. De Winter F, Gemmel F, Van De Wiele C, Poffijn B, Uyttendaele D, Dierckx R. 18-Fluorine fluorodeoxyglucose positron emission tomography for the diagnosis of infection in the postoperative spine. Spine. 2003;28:1314-9. https://doi.org/10.1097/01.brs. 0000065483.07790.34.

76. Schiesser M, Stumpe KD, Trentz O, Kossmann T, Von Schulthess GK. Detection of metallic implant-associated infections with FDG PET in patients with trauma: correlation with microbiologic results. Radiology. 2003;226:391-8. https://doi.org/10.1148/radiol. 2262011939.

77. Hartmann A, Eid K, Dora C, Trentz O, von Schulthess GK, Stumpe KD. Diagnostic value of 18 F-FDG PET/CT in trauma patients with suspected chronic osteomyelitis. Eur J Nucl Med Mol Imaging. 2007;34:704-14. https://doi.org/10.1007/s00259006-0290-4

78. Kwee TC, Kwee RM, Alavi A. FDG-PET for diagnosing prosthetic joint infection: systematic review and metaanalysis. Eur $\mathrm{J}$ Nucl Med Mol Imaging. 2008;35:2122-32. https://doi.org/10. 1007/s00259-008-0887-x.

79. Jin H, Yuan L, Li C, Kan Y, Hao R, Yang J. Diagnostic performance of FDG PET or PET/CT in prosthetic infection after arthroplasty: a meta-analysis. Q J Nucl Med Mol Imaging. 2014;58:85-93.

80. Verberne SJ, Raijmakers PG, Temmerman OP. The accuracy of imaging techniques in the assessment of periprosthetic hip infection: a systematic review and meta-analysis. J Bone Joint Surg Am. 2016;98:1638-45. https://doi.org/10.2106/jbjs.15.00898.

81. Verberne SJ, Sonnega RJ, Temmerman OP, Raijmakers PG. What is the accuracy of nuclear imaging in the assessment of periprosthetic knee infection? A meta-analysis. Clin Orthop Relat Res. 2017;475:1395-410. https://doi.org/10.1007/s11999016-5218-0. 
82. Nawaz A, Torigian DA, Siegelman ES, Basu S, Chryssikos T, Alavi A. Diagnostic performance of FDG-PET, MRI, and plain film radiography (PFR) for the diagnosis of osteomyelitis in the diabetic foot. Mol Imaging Biol. 2010;12:335-42. https://doi.org/ 10.1007/s11307-009-0268-2.

83. Kagna O, Srour S, Melamed E, Militianu D, Keidar Z. FDG PET/ $\mathrm{CT}$ imaging in the diagnosis of osteomyelitis in the diabetic foot. Eur J Nucl Med Mol Imaging. 2012;39:1545-50. https://doi.org/ 10.1007/s00259-012-2183-z.

84. Rojoa D, Kontopodis N, Antoniou SA, Ioannou CV, Antoniou GA. 18F-FDG PET in the diagnosis of vascular prosthetic graft infection: a diagnostic test accuracy meta-analysis. Eur J Vasc Endovasc Surg. 2019;57:292-301. https://doi.org/10.1016/j.ejvs. 2018.08.040.

85. Reinders Folmer EI, Von Meijenfeldt GCI, Van der Laan MJ, Glaudemans A, Slart R, Saleem BR, et al. Diagnostic imaging in vascular graft infection: a systematic review and meta-analysis. Eur J Vasc Endovasc Surg. 2018;56:719-29. https://doi.org/10. 1016/j.ejvs.2018.07.010

86. Keidar Z, Engel A, Hoffman A, Israel O, Nitecki S. Prosthetic vascular graft infection: the role of 18F-FDG PET/CT. J Nucl Med. 2007;48:1230-6. https://doi.org/10.2967/jnumed.107. 040253.

87. Bruggink JL, Glaudemans AW, Saleem BR, Meerwaldt R, Alkefaji H, Prins TR, et al. Accuracy of FDG-PET-CT in the diagnostic work-up of vascular prosthetic graft infection. Eur $\mathrm{J}$ Vasc Endovasc Surg. 2010;40:348-54. https://doi.org/10.1016/j. ejvs.2010.05.016.

88. Auletta S, Varani M, Horvat R, Galli F, Signore A, Hess S. PET radiopharmaceuticals for specific bacteria imaging: a systematic review. J Clin Med. 2019;8. https://doi.org/10.3390/jcm8020197.

89. Nanni C, Boriani L, Salvadori C, Zamparini E, Rorato G, Ambrosini V, et al. FDG PET/CT is useful for the interim evaluation of response to therapy in patients affected by haematogenous spondylodiscitis. Eur J Nucl Med Mol Imaging. 2012;39:153844. https://doi.org/10.1007/s00259-012-2179-8.

90. Husmann L, Ledergerber B, Anagnostopoulos A, Stolzmann P, Sah BR, Burger IA, et al. The role of FDG PET/CT in therapy control of aortic graft infection. Eur J Nucl Med Mol Imaging. 2018;45:1987-97. https://doi.org/10.1007/s00259-018-4069-1.

91. Husmann L, Sah BR, Scherrer A, Burger IA, Stolzmann P, Weber R, et al. (1)(8)F-FDG PET/CT for therapy control in vascular graft infections: a first feasibility study. J Nucl Med. 2015;56:1024-9. https://doi.org/10.2967/jnumed.115.156265.

92. Sjölander H, Strømsnes T, Gerke O, Hess SJC, Imaging T. Value of FDG-PET/CT for treatment response in tuberculosis: a systematic review and meta-analysis. 2018;6:19-29. https://doi.org/10. 1007/s40336-017-0259-2.

93. Basu S, Zhuang H, Torigian DA, Rosenbaum J, Chen W, Alavi A. Functional imaging of inflammatory diseases using nuclear medicine techniques. Semin Nucl Med. 2009;39:124-45. https://doi. org/10.1053/j.semnuclmed.2008.10.006.

94. Zerizer I, Tan K, Khan S, Barwick T, Marzola MC, Rubello D, et al. Role of FDG-PET and PET/CT in the diagnosis and management of vasculitis. Eur J Radiol. 2010;73:504-9. https://doi. org/10.1016/j.ejrad.2010.01.021.

95. Besson FL, Parienti JJ, Bienvenu B, Prior JO, Costo S, Bouvard $\mathrm{G}$, et al. Diagnostic performance of (1)(8)F-fluorodeoxyglucose positron emission tomography in giant cell arteritis: a systematic review and meta-analysis. Eur J Nucl Med Mol Imaging. 2011;38: 1764-72. https://doi.org/10.1007/s00259-011-1830-0.
96. Soussan M, Nicolas P, Schramm C, Katsahian S, Pop G, Fain O, et al. Management of large-vessel vasculitis with FDG-PET: a systematic literature review and meta-analysis. Medicine (Baltimore). 2015;94:e622. https://doi.org/10.1097/md. 0000000000000622.

97. Cheng Y, Lv N, Wang Z, Chen B, Dang A. 18-FDG-PET in assessing disease activity in Takayasu arteritis: a meta-analysis. Clin Exp Rheumatol. 2013;31:S22-7.

98. Barra L, Kanji T, Malette J, Pagnoux C. Imaging modalities for the diagnosis and disease activity assessment of Takayasu's arteritis: a systematic review and meta-analysis. Autoimmun Rev. 2018;17: 175-87. https://doi.org/10.1016/j.autrev.2017.11.021.

99. Nielsen BD, Hansen IT, Kramer S, Haraldsen A, Hjorthaug K, Bogsrud TV, et al. Simple dichotomous assessment of cranial artery inflammation by conventional 18F-FDG PET/CT shows high accuracy for the diagnosis of giant cell arteritis: a case-control study. Eur J Nucl Med Mol Imaging. 2019;46:184-93. https:// doi.org/10.1007/s00259-018-4106-0.

100. Nielsen BD, Gormsen LC, Hansen IT, Keller KK, Therkildsen P, Hauge EM. Three days of high-dose glucocorticoid treatment attenuates large-vessel 18F-FDG uptake in large-vessel giant cell arteritis but with a limited impact on diagnostic accuracy. Eur J Nucl Med Mol Imaging. 2018;45:1119-28. https://doi.org/10. 1007/s00259-018-4021-4.

101. Maestri Brittain J, Gormsen LC, von Benzon E, Andersen KF. Concomitant polymyalgia rheumatica and large-vessel vasculitis visualized on (18)F-FDG PET/CT. Diagnostics (Basel, Switzerland). 2018;8. https://doi.org/10.3390/ diagnostics 8020027.

102. Sondag M, Guillot X, Verhoeven F, Blagosklonov O, Prati C, Boulahdour $\mathrm{H}$, et al. Utility of $18 \mathrm{~F}$-fluoro-dexoxyglucose positron emission tomography for the diagnosis of polymyalgia rheumatica: a controlled study. Rheumatology (Oxford, England). 2016;55:1452-7. https://doi.org/10.1093/ rheumatology/kew202.

103. Rehak Z, Sprlakova-Pukova A, Kazda T, Fojtik Z, Vargova L, Nemec P. (18)F-FDG PET/CT in polymyalgia rheumatica-a pictorial review. Br J Radiol. 2017;90:20170198. https://doi.org/10. 1259/bjr.20170198.

104. Alavi A, Buchpiguel CA, Loessner A. Is there a role for FDG PET imaging in the management of patients with sarcoidosis? J Nucl Med. 1994;35:1650-2.

105. Kwee TC, Torigian DA, Alavi A. Nononcological applications of positron emission tomography for evaluation of the thorax. $\mathrm{J}$ Thorac Imaging. 2013;28:25-39. https://doi.org/10.1097/RTI. 0b013e31827882a9.

106. Treglia G, Annunziata S, Sobic-Saranovic D, Bertagna F, Caldarella C, Giovanella L. The role of 18F-FDG-PET and PET/CT in patients with sarcoidosis: an updated evidence-based review. Acad Radiol. 2014;21:675-84. https://doi.org/10.1016/j. acra.2014.01.008.

107. Kim SJ, Pak K, Kim K. Diagnostic performance of F-18 FDG PET for detection of cardiac sarcoidosis; a systematic review and meta-analysis. J Nucl Cardiol. 2019. https://doi.org/10.1007/ s12350-018-01582-y.

108. Tang R, Wang JT, Wang L, Le K, Huang Y, Hickey AJ, et al. Impact of patient preparation on the diagnostic performance of 18F-FDG PET in cardiac sarcoidosis: a systematic review and meta-analysis. Clin Nucl Med. 2016;41:e327-39. https://doi.org/ 10.1097/rlu.0000000000001063.

109. Treglia G, Quartuccio N, Sadeghi R, Farchione A, Caldarella C, Bertagna F, et al. Diagnostic performance of Fluorine-18- 
Fluorodeoxyglucose positron emission tomography in patients with chronic inflammatory bowel disease: a systematic review and a meta-analysis. J Crohn's Colitis. 2013;7:345-54. https:// doi.org/10.1016/j.crohns.2012.08.005.

110. Zhang J, Li LF, Zhu YJ, Qiu H, Xu Q, Yang J, et al. Diagnostic performance of 18F-FDG-PET versus scintigraphy in patients with inflammatory bowel disease: a meta-analysis of prospective literature. Nucl Med Commun. 2014;35:1233-46. https://doi.org/ $10.1097 / \mathrm{mnm} .0000000000000202$.

111. Lenze F, Wessling J, Bremer J, Ullerich H, Spieker T, Weckesser $\mathrm{M}$, et al. Detection and differentiation of inflammatory versus fibromatous Crohn's disease strictures: prospective comparison of 18F-FDG-PET/CT, MR-enteroclysis, and transabdominal ultrasound versus endoscopic/histologic evaluation. Inflamm Bowel Dis. 2012;18:2252-60. https://doi.org/10.1002/ibd.22930.

112. Malham MHS, Nielse RG, Husby S, Høilund-Carlsen PF. PET/CT in the diagnosis of inflammatory bowel disease in pediatric patients: a review. Am J Nucl Med Mol Imaging. 2014.

113. Carey K, Saboury B, Basu S, Brothers A, Ogdie A, Werner T, et al. Evolving role of FDG PET imaging in assessing joint disorders: a systematic review. Eur J Nucl Med Mol Imaging. 2011;38:193955. https://doi.org/10.1007/s00259-011-1863-4.

114. Sarma M, Vijayant V, Basu S. (18)F-FDG-PET assessment of early treatment response of articular and extra-articular foci in newly diagnosed rheumatoid arthritis. Hell J Nucl Med. 2012;15:70-1.

115. Elzinga EH, van der Laken CJ, Comans EF, Boellaard R, Hoekstra OS, Dijkmans BA, et al. 18F-FDG PET as a tool to predict the clinical outcome of infliximab treatment of rheumatoid arthritis: an explorative study. J Nucl Med. 2011;52:77-80. https://doi.org/10. 2967/jnumed.110.076711.

116. Hess S, Frary EC, Gerke O, Werner T, Alavi A, Høilund-Carlsen PFJC, et al. FDG-PET/CT in venous thromboembolism. 2018;6: 369-78. https://doi.org/10.1007/s40336-018-0296-5.

Publisher's note Springer Nature remains neutral with regard to jurisdictional claims in published maps and institutional affiliations. 